\title{
Bentall procedure: quarter century of clinical experiences of a single surgeon
}

\author{
Kálmán Benke ${ }^{1,3^{*}}$, Bence Ágg ${ }^{1,3}$, Lilla Szabó1, Bálint Szilveszter ${ }^{1,4}$, Balázs Odler², Miklós Pólos ${ }^{1}$, Chun Cao \\ Pál Maurovich-Horvat ${ }^{1,4}$, Tamás Radovits ${ }^{1}$, Béla Merkely ${ }^{1}$ and Zoltán Szabolcs ${ }^{1,3}$
}

\begin{abstract}
Background: We retrospectively analyzed 25 years of experiences with the button Bentall procedure in patients with aortic root pathologies. Even though this procedure has become widespread, there are only a few very long term follow-ups available in the clinical literature, especially regarding single surgeon results.

Methods: Between 1988 and 2013, a total of 147 patients underwent the Bentall procedure by the same surgeon. Among them there were 62 patients with Marfan syndrome. At the time of the surgery the mean age was $46.5 \pm$ 17.6 years. The impact of surgical experience on long-term survival was evaluated using a cumulative sum analysis chart.

Results: The Kaplan-Meier estimated overall survival rates for the 147 patients were $91.8 \pm 2.3 \%, 84.3 \pm 3.1 \%, 76.3 \pm$ $4.9 \%$ and $59.5 \pm 10.7 \%$ at $1,5,10$ and 20 years, respectively. Multivariate Cox regression analysis identified EuroSCORE II over $3 \%$ (OR 4.245, $95 \% \mathrm{Cl}, 1.739-10.364, p=0.002)$, acute indication (OR 2.942, $95 \% \mathrm{Cl}, 1.158-7.480, p=0.023)$, use of deep hypothermic circulatory arrest (OR 3.267, $95 \%$ Cl, 1.283-8.323, $p=0.013)$, chronic kidney disease (OR 6.865, $95 \%$ $\mathrm{Cl}, 1.339-35.189, p=0.021)$ and early complication (OR 3.134, $95 \% \mathrm{Cl}, 1.246-7.883, p=0.015)$ as significant risk factors for the late overall death. The survival rate for freedom from early complication was $94.3 \pm 2.2 \%, 88.0 \pm 3.3 \%, 82.9 \pm$ $4.7 \%$ and $69.2 \pm 8.4 \%$ at $1,5,10$ and 20 years. The main pathological findings of the aortic wall were cystic medial degeneration in $75 \%$, fibrosis in $6 \%$, atherosclerosis in $13 \%$ and no pathological alteration in $6 \%$ of the samples. The overall survival rate was significantly lower in patients operated in first 15 years compared to patients operated in the last decade (log-rank $p=0.011)$.

Conclusion: According to our long-term follow-up the Bentall operation provides an appropriate functional result by resolving the lesions of the ascending aorta. Based on our results, 25-30 operations done is necessary to gain such a level of confidence and experince to aquire better results on long-term survival. In addition, we discussed that there were no co-morbidities affecting on the survival of Marfan patients and prophylactic aortic root replacement ensures a longer survival among patients with Marfan syndrome.
\end{abstract}

Keywords: Bentall procedure, Aortic root reconstruction, Cardiac surgery, Single surgeon experience

\section{Background}

Aortic root replacement procedures, which include the modified version of the original Bentall [1] operation, the "button Bentall procedure", which is an open technique for reattaching the coronary ostia. Although this procedure has become widespread, there are only a few very

\footnotetext{
* Correspondence: kalman.benke@gmail.com

${ }^{1}$ Heart and Vascular Center, Semmelweis University, H-1122 Városmajor str. 68, Budapest, Hungary

${ }^{3}$ Hungarian Marfan Foundation, Budapest, Hungary

Full list of author information is available at the end of the article
}

long term follow-ups available in the clinical literature. We evaluated the long-term clinical outcomes and sought to determine the independent predictors of longterm mortality for the button Bentall procedure in 147 patients [2]. We analyzed the independent risk factors of long-term mortality in a subdivided Marfan population too. Furthermore, there has been no study published yet about experience and results of a single surgeon in Bentall procedure. 


\section{Methods}

\section{Patients' characteristics}

We retrospectively analyzed 25 years of experience with Bentall procedure. Between 1988 and 2013, a total of 147 patients who underwent aortic root reconstruction at the Heart and Vascular Center, Semmelweis University. Of these patients, 111 (75\%) were male and 36 were female (25\%). 62 patients were with Marfan syndrome (42\%) among them and the diagnosis of the syndrome was verified in every case with the use of the original and later the revised Ghent criteria [3]. Subanalysis of the Marfan syndrome group was performed.

An electronic Aortic Root Reconstruction Registry database has been established which includes demographics, types of indications, comorbidities, procedure specifications and follow-up informations. Medical records and patient's history were used to identify comorbidities. Patients' follow-ups included clinical examination, computed tomography scans and transthoracic echocardiography, and they were treated by the same surgeon. During the studied period, Tirone David valve-sparing procedures were performed in 27 patients. These patients were excluded from the study.

The mean patient age at the time of the operation was $46.3 \pm 17.5$ years (range, $8-78$ years), 8 (5\%) patients were older than 70 years. We measured body parameters of patients (height and weight), and calculated the Body Mass Index. The mean BMI was $25.6 \pm 5.6 \mathrm{~kg} / \mathrm{m}^{2}$. We found that 80 patients had hypertension (54\%), 11 patients had diabetes mellitus (7\%) and 6 had hyperlipidaemia (4\%). 21 patients were suffering from coronary artery disease (14\%) at the time of the operation, 4 from chronic kidney disease ( $3 \%$ ) and 7 patients had cerebrovascular accident (5\%). The cardiovascular functional status was determined according to the New York Heart Association (NYHA). EuroSCORE II was calculated in all patients according to the EuroSCORE II protocol [4]. The histology of the aortic wall and valve were available in 114 patients (78 \%). The main indications of the operation were annuloaortic ectasia (61\%), acute aortic dissection (16\%) and chronic aortic dissection (23\%). Preoperative variables are depicted in Table 1.

\section{Surgical technique}

The operation was performed via median sternotomy, and cardiopulmonary bypass was applied by cannulating the ascending aorta, aortic arch, femoral artery, or axillar artery, and the right atrium. Myocardial protection was provided by anterograde, retrograde, or simultaneously anterograde and retrograde intermittent cold hyperkalemic blood cardioplegia. Deep hypothermic circulatory arrest (DHCA) was used in 28 patients (19\%). The coronary buttons were excised with the aortic wall patch and mobilized to facilitate reimplantation. The proximal
Table 1 Preoperative characteristics

\begin{tabular}{ll}
\hline Preoperative variables & $\mathrm{n}(\%)$ \\
\hline Patients & 147 \\
Age (yrs) \pm SD & $46.3 \pm 17.5$ \\
Male/Female & $111 / 36(75 / 25)$ \\
Hypertension & $80(54)$ \\
Diabetes mellitus & $11(7)$ \\
Coronary artery disease & $21(14)$ \\
HLP & $6(4)$ \\
BMI (kg/m²) & $25.6 \pm 5.6$ \\
Cerebrovascular accident & $7(5)$ \\
Chronic kidney disease & $4(3)$ \\
NYHA class & $1.3 \pm 0.6$ \\
EuroSCORE II (\%) & $4[2-6]$ \\
Aorta ascendens diameter (mm) & $61.7 \pm 16.3$ \\
Marfan syndrome & $62(42)$ \\
Previous Cardiac Operation & $6(4)$ \\
Grade of aortic regurgitation & $2.8 \pm 1.5$ \\
Ejection fraction (\%) [before OP / after OP] & $49.6 \pm 8.3 / 54.33 \pm 11.17$ \\
All-cause death & $29(20)$ \\
\hline
\end{tabular}

anastomosis was implemented with pledgeted interrupted sutures. The distal, grafto-aortic anastomosis was accomplished with continuous sutures and the coronary button anastomoses were also performed with continuous sutures.

St. Jude composite graft (St. Jude Medical, Inc., St.Paul, MN, USA) was used in 101 patients; Carbomedics composite graft (Carbomedics, Austin, TX, USA) in 16 patients; Carbomedics Carbo-Seal conduit (Sorin, Milano, Italy) in 18 patients; Vascutek Gelweave composite graft (Vascutek, Scotland, UK) in 5 patients; Hancock bioprosthesis (Medtronics, Minneapolis, Minnesota, USA) with Vaskutek straight graft in 5 patients; and Shelhigh bioconduit (Shelhigh, Union, NJ, USA) in 2 patients. The 7 bioprosthetic valve and graft were compiled together by the surgeon during operation.

The concomitant procedures were performed in 39 patients $(27 \%)$; included mitral valve surgery in 11 , coronary artery bypass grafting (CABG) in 12, hemi- and total arch replacement in 10 , pacemaker implantation in 2 , and others in 4 patients. Operative data are described in Table 2.

\section{Follow-up and statistical analysis}

We selected all-cause mortality as the endpoint. No patient was lost during the follow-up period. Death was detected from death records of the Hungarian National Health Insurance Fund, which provided accurate mortality data for every patient. Follow-up period for the overall survival was measured from the date of the operation to the date of death, or of last contact alive. Follow-up ended on October 2013. 118 patients (80 \%) of survivors had 
Table 2 Operative data

\begin{tabular}{ll}
\hline Operative data & $\mathrm{n}(\%)$ \\
\hline Aortic pathology & $89(61)$ \\
Annuloaortic ectasia & $24 / 34(16 / 23)$ \\
Dissection (acute/chronic) & $11(7)$ \\
Bicuspid aortic valve & \\
Implanted valve type & $140(95)$ \\
Mechanical valve & $7(5)$ \\
Bioprosthetic valve & $25.9 \pm 1.7$ \\
Composite valve size (mm) & \\
Comcomitant cardiac procedures & $11(7.5)$ \\
Mitral valve surgery & $12(8)$ \\
Coronary artery bypass & $10(7)$ \\
Total arch replacement & $2(1)$ \\
Pacemaker implantation & $4(2)$ \\
Others & \\
Cardiopulmonary bypass & $245[210-305]$ \\
Operation time (min) & $155[130-185]$ \\
Cardiopulmonary bypass time (min) & $113[100-137]$ \\
Aortic cross-clamp time (min) & $28(19)$ \\
DHCA use & $25.6 \pm 6.1$ \\
Pharyngeal temperature (C) & \\
Timing of operation & $24(16)$ \\
Urgency & $34(23)$ \\
\hline
\end{tabular}

completed follow-up. The mean length of the follow-up periods was $84 \pm 56$ months.

All continuous variables were expressed as mean \pm SD or median with interquartile ranges, whereas categorical variables were expressed as percentage. The ShapiroWilk test was used to check the normality of the data before further analysis. For the analysis of the data we used Student's $t$-test, Mann-Whitney $U$-test and $\chi 2$ test. Univariate and multivariate analysis of predictors for mortality were performed using a Cox regression model evaluate the association between independent risk factors and mortality. Survival curves were created using the Kaplan-Meier method and compared with the logrank test. Multivariate logistic regression analysis was used to identify the risk factors of early complication.

We used univariate and multivariate Cox regression analysis to evaluate the effect of comorbidities on mortality. Multivariate Cox regression identified the independent risk factors of long-term mortality after Bentall procedure. The determination of risk factors was carried out by selecting variables with $p<0.10$ from univariate Cox regression, and further examined our data with multivariate Cox regression analysis. A $p$-value of $<0.05$ was considered statistically significant (Table. 4).
The impact of surgical experience on survival was evaluated using a time-adjusted cumulative sum complication chart. The statistical principles were adapted from the comprehensive tutorial by Rogers et al. [5]. Cumulative sum (CUSUM) analysis is defined as $\mathrm{Sn}=\left(\mathrm{X}_{\mathrm{i}}-\mathrm{p} \mathrm{O}_{\mathrm{i}}\right)$, where $\mathrm{X}_{\mathrm{i}}=0$ for operation without complication and 1 for the presence of early complication, and $\mathrm{p} 0_{\mathrm{i}}$ denotes the predicted probability of the development of early complication within 30 days after surgery. The graph starts at zero, but is incremented by $1-\mathrm{p} 0_{i}$ for formation of early complication and decremented by $\mathrm{p}_{\mathrm{i}}$ for uncomplicated operation [6] This graph is very descriptive because it moves upwards if the complication rate increases above the risk model predicted results, moves downwards if the rate decreases and oscillates around zero performance which is consistent with predicted risks thus is considered as acceptable [6]. Data were stored in Aortic Root Reconstruction Register and analysed with the SPSS statistical program (version 20.0,Chicago, IL, USA).

\section{Results}

Early outcomes

The operative mortality was $2 \%$. The overall early mortality rate, defined as death within 30 days of initial hospitalization, was $3.4 \%(5 / 147)$. Causes of early death were low cardiac output syndrome $(n=1)$, diffuse hypoxic brain damage $(n=2)$, ventricular arrhytmia $(n=1)$ and excess bleeding in 1 patient. Early complications included postoperative resternotomy for bleeding $(n=9)$, atrial and ventricular arrhytmias $(n=13)$, renal failure needing hemodialysis $(n=1)$, cerebral infarction $(n=2)$ and pericardial tamponade $(n=1)$ (Table 3$)$.

Multivariate logistic regression analysis revealed, that NYHA class of III and IV (OR 9.2, 95 \% CI, 0.972-87.240, $p=0.050$ ), dissection (OR 6.817, 95 \% CI, 1.392-33.393, $p=0.018$ ), concomitant CABG surgery (OR 15.722, $95 \% \mathrm{CI}, 3.087-80.064, p=0.001)$ and concomitant

Table 3 Causes of complications

\begin{tabular}{ll}
\hline Complications & $\mathrm{n}(\%)$ \\
\hline Intraoperative complications & $7(5)$ \\
Bleeding & $3(2)$ \\
Arrythmia & \\
Early postoperative complications & $9(7)$ \\
Bleeding & $2(1)$ \\
Diffuse cerebral hypoxia & $1(0.7)$ \\
Pericardial tamponade & $1(0.7)$ \\
Renal failure needed hemodialysis & $13(9)$ \\
Arrythmia & \\
Late postoperative complications & $1(0.7)$ \\
Bleeding & $2(1)$ \\
Arrythmia & \\
\hline
\end{tabular}


mitral valve surgery (OR 5.207, $95 \%$ CI, 0.987-27.480, $p=0.049$ ) were the independent risk factors for early complication, which defined as possible life-threathening complication within 30 days of initial hospitalization (Table 5).

\section{Long-term results}

The mean survival was $190 \pm 10.3$ months (IQ range:170210 months). There have been 23 late deaths (death after one year), whereof 18 cardiac-related (78 \%) and 5 noncardiac-related (22\%) deaths occured. The most common causes of cardiac-related death were aneurysm rupture of descending aorta, sudden cardiac death, congestive heart failure, CVA and low cardiac output syndrome.

Kaplan-Meier estimated overall survival rates for the 147 patients (including deaths occured at the initial hospitalization) were $91.8 \pm 2.3 \%, 84.3 \pm 3.1 \%, 76.3 \pm$ $4.9 \%$ and $59.5 \pm 10.7 \%$ at $1,5,10$ and 20 years, respectively (Fig. 1a). Multivariate Cox regression analysis identified EuroSCORE II over 3 \% (OR 4.245, 95 \% CI, 1.739-10.364, $p=0.002$ ), acute indication (OR 2.942, $95 \%$ CI, 1.158-7.480, $p=0.023$ ), DHCA use (OR 3.267, $95 \%$ CI, 1.283-8.323, $p=0.013)$, chronic kidney disease (OR 6.865, $95 \%$ CI, 1.339-35.189, $p=0.021$ ), and early complication (OR 3.134, $95 \% \mathrm{CI}, 1.246-7.883, p=0.015$ ) as significant risk factors for the late overall death (Table 6).

\section{Influence of Marfan syndrome on survival}

We have separated the patients into two groups: patients with Marfan syndrome (Marfan group), and patients without Marfan syndrome (non-Marfan group) (Table 4). Multivariate regression analysis of all patients' data revealed, that
EuroSCORE II over 3 \% (OR 5.612, 95 \% CI, 1.761-17.884, $p=0.004$ ) and acute indication (OR 6.391, 95 \% CI, 1.37329.750, $p=0.018$ ) were the independent risk factors for mortality (Table 5). Among the patients with Marfan syndrome, the overall survival rate did not reach statistical significance ( $\log$ rank $p=0.877$ ) compared to the non-Marfan group (Fig. 1b).

\section{Outcome of dissections}

Overall survival rate differed between the non-dissection group and the dissection group. In the latter group the results were significantly lower according to the log-rank test $(p=0.031)$ (Fig. 2a). However in Marfan syndrome patients with dissection, the overall survival rate tended to decline compared to the dissection group without Marfan syndrome and to the non-dissection group (Fig. 2b).

\section{Histopathology of the aortic wall and valve}

During the operation aortic wall and valve samples were collected and sent for pathological examination. The main pathological findings unearthed were cystic medial degeneration (CMD) in 85 samples (75\%), fibrosis in 7 samples (6\%), atherosclerosis in 15 samples (13\%) and no pathological alteration in 7 samples (6\%). Overall survival rates between the patients with CMD, patients with fibrosis and patients with atherosclerosis were similar (CMD vs. fibrosis log-rank $p=0.197$; CMD vs. atherosclerosis log-rank $=0.400$; fibrosis vs. atherosclerosis $\log$-rank $p=0.876$ ) Fig. 2.

\section{Impact of surgical experience on survival}

We have compared the first 15 years of results to the last 10 years of results to investigate the influence of surgical

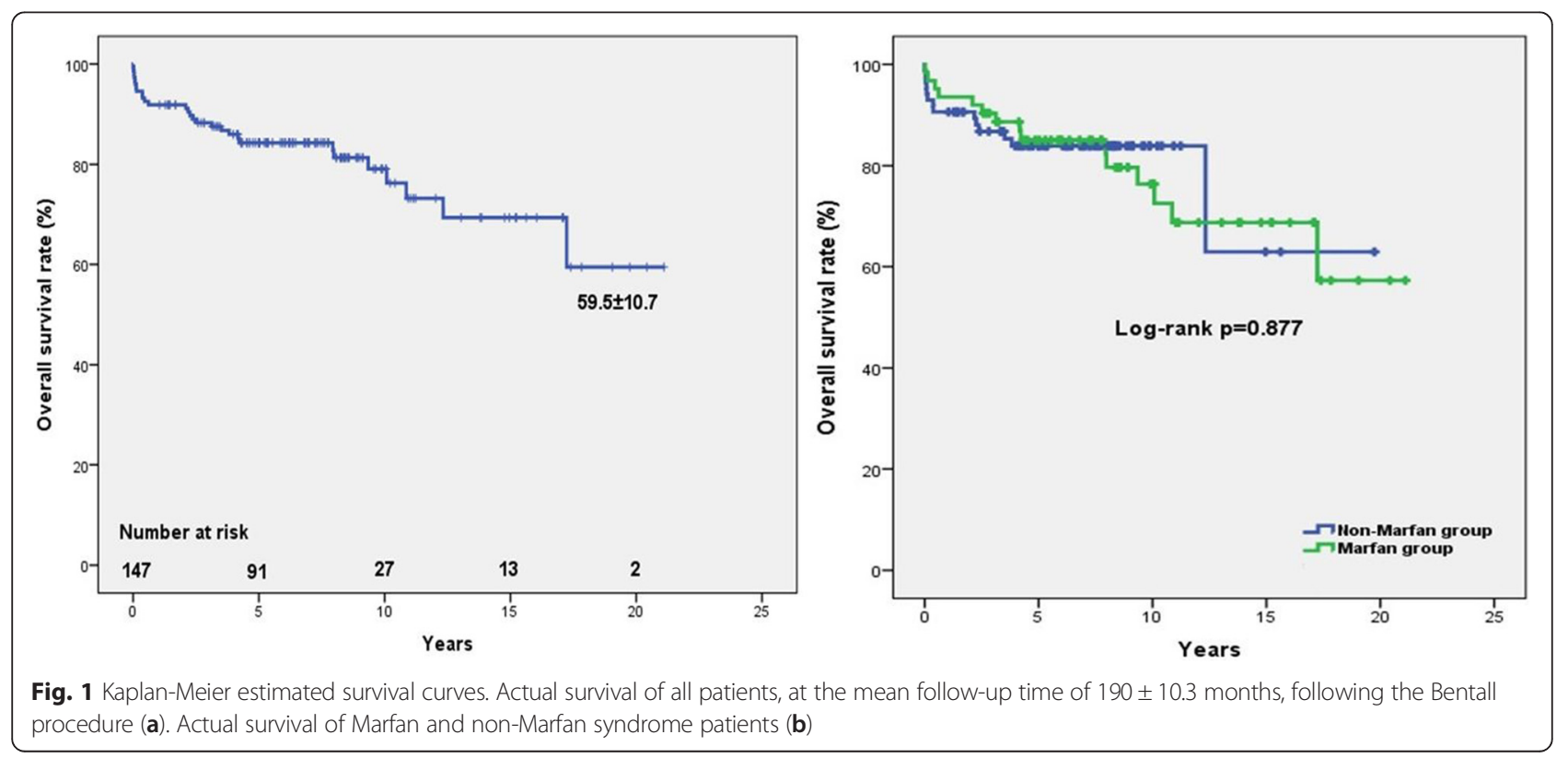


Table 4 Risk factor analysis for late overall death

\begin{tabular}{|c|c|c|c|c|}
\hline \multirow[t]{2}{*}{ Variables } & \multicolumn{2}{|c|}{ Patients $(n=147)$} & \multicolumn{2}{|c|}{ Patients with Marfan syndrome $(n=62)$} \\
\hline & Univariate & $\overline{\text { Multivariate }}$ & Univariate & Multivariate \\
\hline Age & 0.821 & & 0.584 & \\
\hline Sex (male) & 0.097 & 0.089 & 0.226 & \\
\hline Hypertension & 0.141 & & 0.156 & \\
\hline Diabetes mellitus & 0.348 & & - & \\
\hline Hyperlipidaemia & 0.577 & & 0.787 & \\
\hline $\mathrm{BMI}>30$ & 0.448 & & 0.335 & \\
\hline Coronary artery disease & 0.167 & & 0.390 & \\
\hline Cerebrovascular accindent & 0.505 & & 0.682 & \\
\hline Chronic kidney disease & $0.011^{\mathrm{a}}$ & $0.036^{\mathrm{a}}$ & 0.683 & \\
\hline EuroSCORE II > $3(\%)$ & $<0.0001^{\mathrm{a}}$ & $0.002^{\mathrm{a}}$ & $<0.0001^{\mathrm{a}}$ & $0.004^{\mathrm{a}}$ \\
\hline Aortic diameter $>60 \mathrm{~mm}$ & 0.211 & & 0.369 & \\
\hline Bicuspid aortic valve & 0.538 & & - & \\
\hline Emergency & $0.006^{\mathrm{a}}$ & $0.023^{\mathrm{a}}$ & $0.006^{\mathrm{a}}$ & $0.018^{\mathrm{a}}$ \\
\hline Combined mitral valve surgery & 0.856 & & 0.547 & \\
\hline Combined CABG surgery & 0.062 & & 0.701 & \\
\hline Combined with arch replacement & 0.855 & & 0.995 & \\
\hline Ejection fraction $<50 \%$ & 0.681 & & 0.252 & \\
\hline LVESD & 0.805 & & 0.370 & \\
\hline LVEDD & 0.534 & & 0.206 & \\
\hline Dissection & $0.035^{\mathrm{a}}$ & 0.136 & 0.094 & 0.476 \\
\hline CPB time & $0.002^{\mathrm{a}}$ & 0.710 & 0.982 & \\
\hline Operation time $>5 \mathrm{~h}$ & $0.002^{\mathrm{a}}$ & 0.224 & 0.102 & \\
\hline DHCA use & $0.004^{\mathrm{a}}$ & $0.013^{\mathrm{a}}$ & 0.597 & \\
\hline Aortic cross-clamp time & 0.753 & & 0.800 & \\
\hline Early complication & $0.035^{\mathrm{a}}$ & $0.015^{\mathrm{a}}$ & 0.190 & \\
\hline
\end{tabular}

${ }^{a_{\text {statistically significant }}}$

Table $\mathbf{5}$ Independent predictors of late overall mortality in multivariate cox regression analysis

\begin{tabular}{llcl}
\hline Variables & \multicolumn{4}{l}{ Patients $(n=147)$} & \\
& OR & $95 \% \mathrm{Cl}$ & $P$-value \\
EuroSCORE II $>3 \%$ & 4.245 & $1.739-10.364$ & 0.002 \\
Emergency & 2.942 & $1.158-7.480$ & 0.023 \\
DHCA use & 3.267 & $1.283-8.323$ & 0.013 \\
Chronic kidney disease & 6.865 & $1.339-35.189$ & 0.021 \\
Early complication & 3.134 & $1.246-7.883$ & 0.015 \\
& Patients with Marfan syndrome $(n=62)$ \\
EuroSCORE II > 3 & OR & $95 \% \mathrm{Cl}$ & $P$-value \\
Emergency & 5.612 & $1.761-17.884$ & 0.004 \\
\hline
\end{tabular}

experience on survival. From 1998 till the end of 2003 42 patients were operated (29\%). The other 105 patients were operated at the next decade $(71 \%)$. The overall survival rate was significantly lower in patients operated in first 15 years compared to patients operated in the last decade (log-rank $p=0.011$ ) (Fig. 4a). The time-adjusted CUSUM complication curve for the entire follow-up time is illustrated in (Fig. 3b). The CUSUM curve presents an upward inflection at the first 27 operation, which indicates the major learning curve effect. After that, we observed a downward inflection, indicating better results and the experience of the surgeon with respect to the predicted complication rates. Specially, we observed three complication between operations no. 121 and no. 124. This cluster of complications necessitated a review. We found that these patients were fragile, multimorbid and urgent cases, than the other as evidenced by the higher predicted probability of complication. 

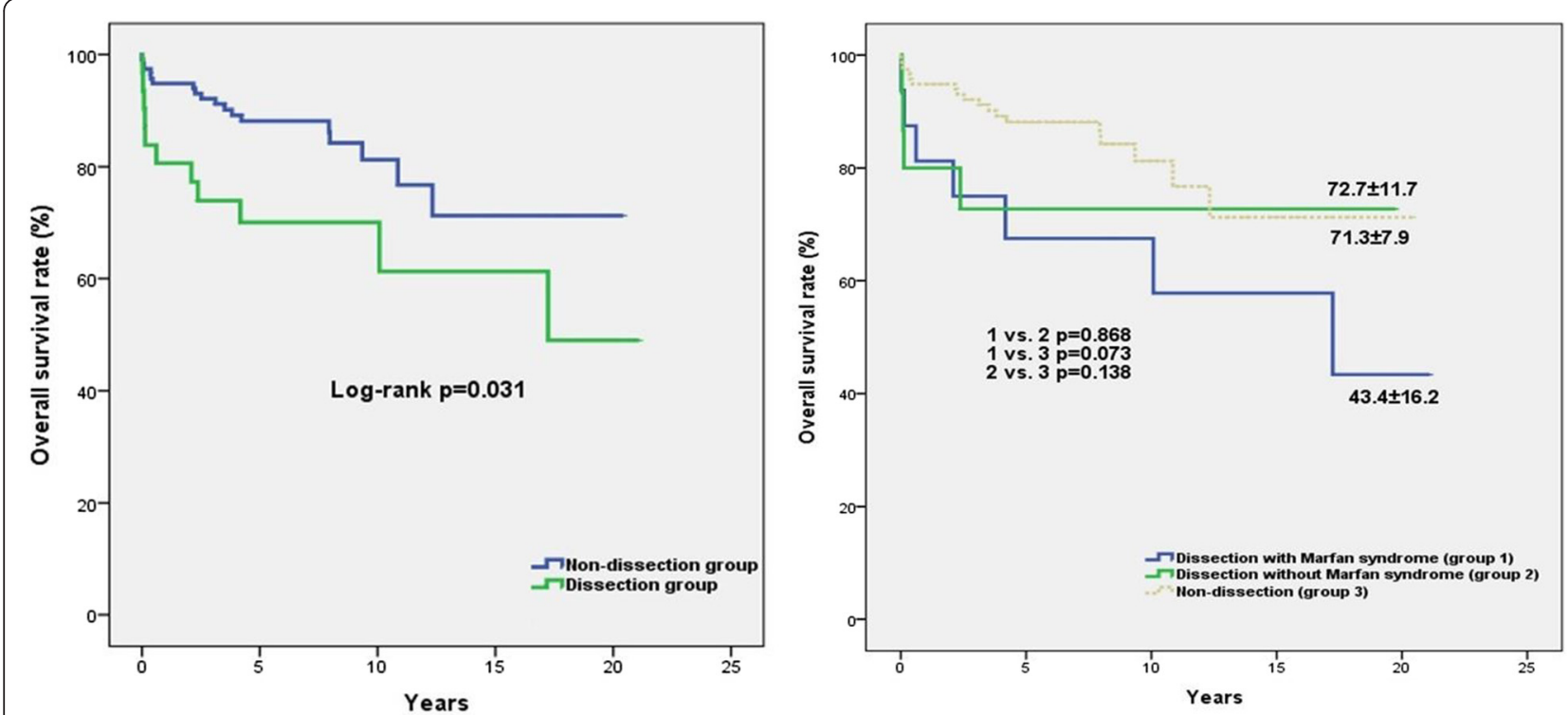

Fig. 2 Kaplan-Meier estimated survival curves. Actual survival rate for non-dissection and dissection patients (a). Actual survival of dissection with Marfan syndrome (group 1), dissection without Marfan syndrome (group 2) and non-dissection (group 3) patients (b)

\section{Discussion}

The mean survival in our study was $190 \pm 10.3$ months (IQ range:170-210 months). There are only few papers published about the Bentall procedure which include mean follow-up duration of more than six years (Table 6).

In our study, we report that the independent predictors of early complication include NYHA class of III and IV, dissection and concomitant CABG or mitral valve surgery. The poor cardiac condition might often associated with early arrythmias, while aortic dissection is a well-known risk factor of the bleeding events.[7]

Numerous studies have shown different independent risk factors for death after Bentall procedure [8, 9]. Advanced age, dissection, Marfan syndrome, severe ventricular dysfunction, endocarditis, previous cardiac surgery, emergency status, coronary artery disease, poor preoperative New York Heart Association functional class and left ventricle ejection fraction $<35 \%$ were known as predictors of early and late death.[8, 9] We observed that late overall death was strongly correlated with EuroSCORE II over $3 \%$, acute indication, DHCA use, chronic kidney disease and early complication thus all the above mentioned factors seem to be independent risk factors of late mortality. In regard that common causes of late death such as rupture of descendent aorta aneurysm, sudden cardiac death, congestive heart failure, CVA, low cardiac output syndrome are associated with poor NYHA status and complications [8]. We found that in our research operative mortality and long-term survival after Bentall surgery were comperable to that in other studies $[2,8,10]$. With improvements in operative technique and postoperative management years, Marfan syndrome, diabetes, hypertension, bicuspid aortic valve, hyperlipidaemia, coronary artery disease, cerebral vascular accident, concomitant cardiac surgery, longer operation, aortic crossclamp time and dissection did not prove to be risk factors for mortality in this study.

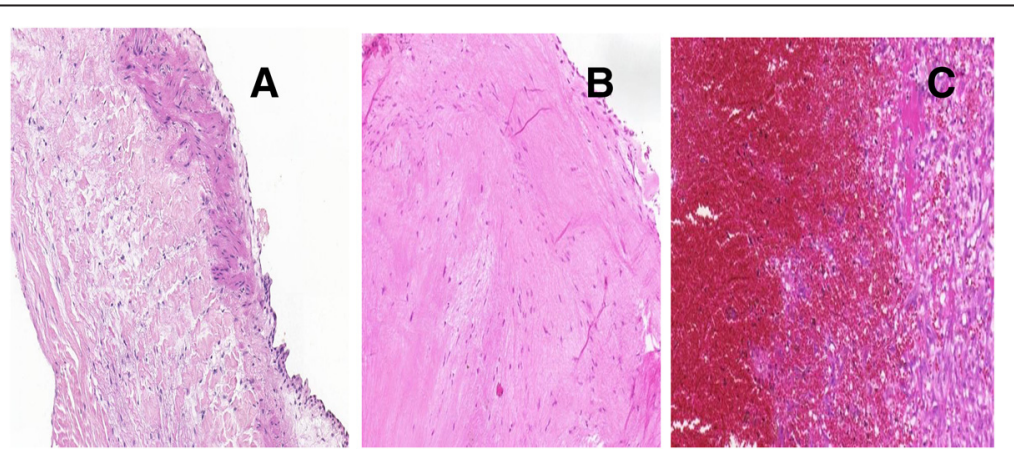

Fig. 3 Histological findings of the aortic wall. Cystic medial degeneration (a) in $75 \%$, fibrosis (b) in $6 \%$, atherosclerosis (c) in $13 \%$ of the samples 
Table 6 Previous reports about Bentall operation

\begin{tabular}{lllll}
\hline Author & Patient group & Follow-up & $\begin{array}{l}\text { Early complication } \\
\text { rate (\%) }\end{array}$ & $\begin{array}{l}\text { Long-term survival at } \\
\text { 5/10/20 years (\%) }\end{array}$ \\
\hline Tae Sik Kim et al. [2] & $n=195,1997-2010,47$ patients with MFS & median, 64 months & 48.7 & $96 / 90 /-$ \\
Patel et al. [21] & $n=140$ Marfan patients, 1997-2006 & mean, 114 months & 21.5 & $90 /-/-$ \\
Gott et al. [20] & $n=675$ patients with MFS, 1968-1996 10 centers & mean, 80 months & - & $84 / 75 /-$ \\
Kouchoukos et al. [7] & $n=168,1974-1990,30$ patients with MFS & mean, 81 months & - & 81 at 7 years/ 48 at 12 years/- \\
Joo et al. [11] & $n=218,1982-2010$ & mean, 108 months & 48.1 & $84 / 78 /-$ \\
Benke et al. & $n=147,1988-2013,62$ patients with MFS & mean, 84 months & 25.5 &
\end{tabular}

There are many debates as to whether Marfan syndrome had an influence in long-term survival after the Bentall procedure. Although several papers have been published $[2,8,11]$, on the subject regarding the impact of presence of Marfan syndrome on survival rate, but only few of them studied the Marfan group as a separate patient group. Since Marfan patients are usually operated in younger age and with less comorbidities [12], therefore they should be managed as a distinct patient group. We presented the risk factors of mortality of the Marfan patients separately. In our study, EuroSCORE II over $3 \%$ and acute indication were significant predictors of long-term mortality among patients with Marfan syndrome. These results also confirm, that there were no co-morbidities affecting the survival of Marfan patients. However the prevention of the acute, often lifethreatening complications - such as aortic dissection with prophylactic aortic root replacement ensures longer survival among patients with Marfan syndrome [13]. There was a trend for decreased survival of patients with Marfan syndrome in the course of time compared to that of non-Marfan patients (Fig. 1b), but we could not find a significant difference in long-term survival $(p=0.877)$ [14]. In our study acute or chronic dissection was the surgical indication in 58 cases. Overall survival rates among the dissection groups were comparable to other reports [11].

The long-term survival of the cardiac procedures are examined from the perspective of the duration of the operation [8]. In our series, thirty-six (24\%) patients had a longer, than five hours operation time. The risk factors of extended duration operations were NYHA class of III and IV, dissection, concomitant mitral valve surgery and DHCA use. According to these results, poor NYHA status and the extension of the surgical area increases the length of the surgery, thus patients with worse cardiac status (EF:30-40 \%) should be treated for preconditioning with inta-aortic balloon pump (IABP) or with $24 \mathrm{~h}$ levosimendan infusion preoperatively.

Although we had incomplete data in 33 cases, histological differences has never been investigated in Bentall studies. In our study, distribution of the histological type were cystic medial degeneration (CMD) in 85 samples (75\%), which is also known as the pathological change of the aortic wall in Marfan patients [15]. Furthermore there were fibrosis in 7 samples (6\%), atherosclerosis in 15 samples (13\%) and no pathological changes in 7 samples $(6 \%)$. The survival rates were not different compared to each other among patients with abnormal histological evidence. (CMD vs. fibrosis log-rank $p=0.197$; CMD vs. atherosclerosis log-rank $=0.400$; fibrosis vs. atherosclerosis log-rank $p=0.876$ ) (Fig. 2).

During the cardiothoracic training surgeons need to gain experience in Bentall procedure. Hence the surgeon launches on a 'learning curve', and unfortunately, his/her patients may possibly be at a higher risk [6]. The traditional way of the surgical audit with retrospective analysis of outcome data and statistical testing is an appropriate method to estimate the learning curve. However, when this is not the case the CUSUM curve is more suitable for this kind of analysis [16]. Hence several publications have used the CUSUM method to asses surgical results in cardiac surgery $[16,17]$. However we found no data about the learning curve of the button Bentall procedure. In this study single surgeon results were demonstrated, therefore we could apply the time adjusted cusum complication curve to this case (Fig. 4b). At the beginning the CUSUM curve starts with an upward inflection, which indicates the major learning curve effect. Based on our findings after 27 operations the risk of the early complications started to reduce. This reflects according to our findings, that approximately 25-30 operations are necessary to aquire better results on survival. After that, we observed a downward inflection, indicating better results and an increase in the experience of the surgeon with respect to the predicted complication rates. Subsequently, when the surgeon felt confident with this procedure, he started to consider those patients in worse condition suitable for Bentall surgery and this may have resulted in a small assessment of the curve (Fig. 4b).

Additionally, after comparing the first fifteen years of surgical results to the last decade the overall survival 

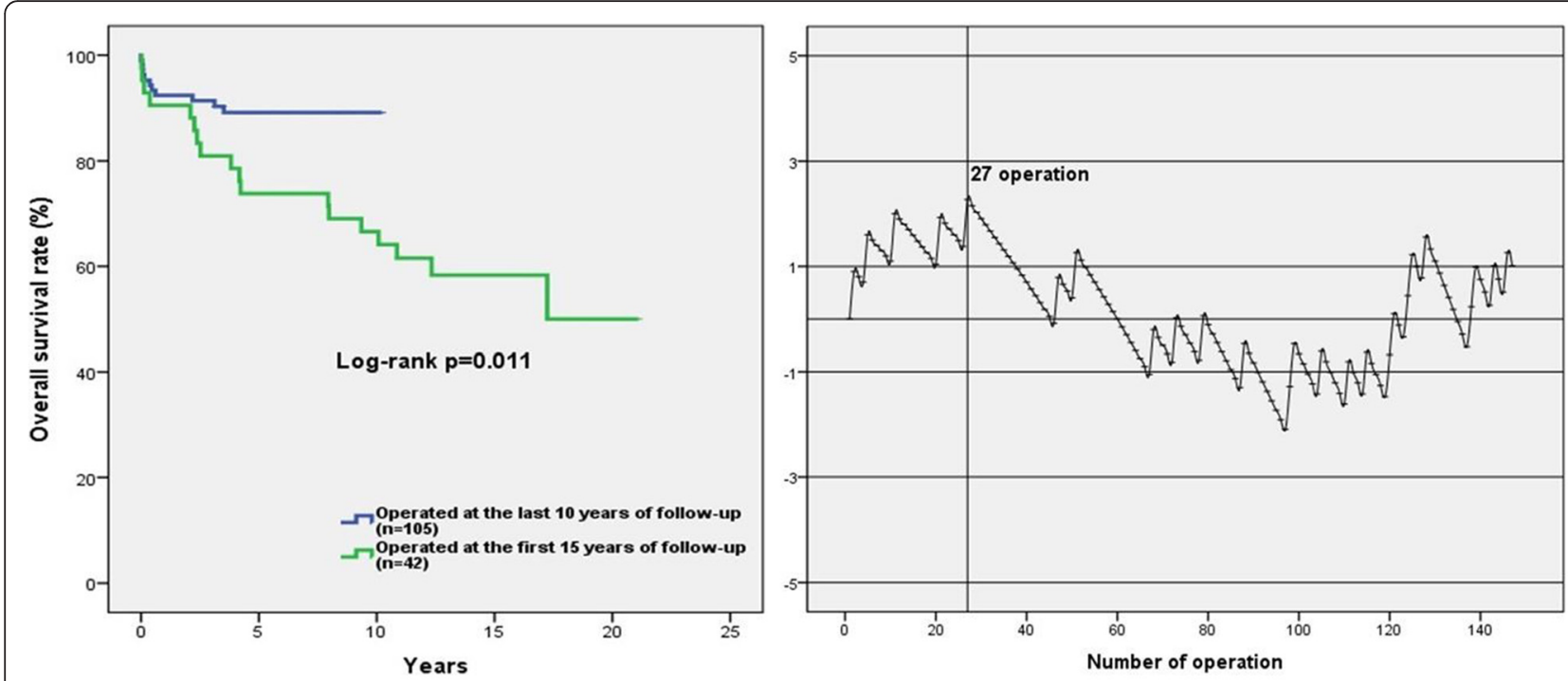

Fig. 4 Actual survival of patients operated at the first fifteen years of follow-up and patients operated in the last decade (a). The risk-adjusted CUSUM complication curve for the entire follow-up (b)

rate we found that the results were significantly lower in first 15 years operated group than the last 10 years operated group (log-rank $p=0.011)$ (Fig. 4a).

Our paper has some limitations that are unaviodable in a retrospective study. Observational data do not provide casual evidence. After fifteen years of observation time only $10 \%$ of of patients still at risk which is a limitation. Due to incomplete data collection, several important variables, such as ejection fraction after surgery and pharyngeal temperature, were omitted in the statistical analysis. The histology of the aortic wall could not be included in logistic regression analysis due to the missing 33 samples. In our study only two pseudoaneurysm formations was observed at the graft anastomosis sites $[18,19]$, but none of them were Marfan patient. The estimation of odds ratios, with regard to chronic kidney disease $(n=4)$ and NYHA class of III and IV in Marfan patients $(n=2)$, could not be carried out in logistic regression analysis due to the low number of events.

\section{Conclusion}

In summary, as this study was performed from the data of one surgeon, gives us the opportunity to describe the learning curve of the button Bentall procedure and follow the results through his course of carrier. In our series, 25-30 operations gave the surgeon confidence and experince to aquire better results on long-term survival. In addition, we discussed that there were no co-morbidities affecting on the survival of Marfan patients and prophylactic aortic root replacement ensures a longer survival among patients with Marfan syndrome. Finally, upon the statistical results we discussed histological changes of the aortic wall, which has never been described in long-term button Bentall followups.

\section{Abbreviations}

MFS: Marfan syndrome; CUSUM: Cumulative sum; DHCA: Deep hypothermic circulatory arrest; CMD: Cystic medial degeneration; BMI: Body mass index; NYHA: New York Heart Association; CABG: Coronary artery bypass graft; IQ: Interquartile; CVA: Cerebral vascular accident; SD: Standard deviation; LVESD: Left ventricular end systolic diameter; LVEDD: Left ventricular end diastolic diameter; CPB: Cardiopulmonary bypass; IABP: Intra-aortic balloon pump.

\section{Competing interests}

The authors declare that they have no competing interests.

\section{Authors' contributions}

KB carried out the data collection, participated in the analysis and interpretation of clinical data, drafted the manuscript and performed the statistical analysis. BÁ carried out the collection of the data, participated in the analysis and interpretation of clinical data, drafted the manuscript and performed the statistical analysis. LSZ also carried out the data collection. BSZ carried out the collection of the date too, and participated in the statistical analysis. BO participated in the statistical analysis process. MP participated in the collection of the data, drafted the manuscript and revised the intellectual content. CC also drafted the manuscript. PM revised the intellectual content. TR participated in the design of the study and revised the intellectual content. BM revised the manuscript and provided professional advices and institutional background. ZSZ conceived of the study, performed all of the surgical procedures, and helped to draft the manuscript. All authors read and approved the final manuscript.

\section{Funding}

This study was supported by grants from the Hungarian Marfan Foundation and by the János Bolyai Research Scholarship of the Hungarian Academy of Sciences (to T. R.).

\section{Author details}

'Heart and Vascular Center, Semmelweis University, H-1122 Városmajor str. 68, Budapest, Hungary. ${ }^{2}$ Department of Pulmonology, Semmelweis University, Budapest, Hungary. ${ }^{3}$ Hungarian Marfan Foundation, Budapest, Hungary. ${ }^{4}$ MTA-SE Lendület Cardiovascular Imaging Research Group, Heart and Vascular Center, Semmelweis University, Budapest, Hungary. 
Received: 21 June 2015 Accepted: 19 January 2016

Published: 22 January 2016

\section{References}

1. Bentall $H$, De Bono A. A technique for complete replacement of the ascending aorta. Thorax. 1968;23:338-9.

2. Kim TS, Na C-Y, Sam Sae O, Kim JH. Long-term mortality and morbidity after Button Bentall operation. J Card Surg. 2013;28:280-4.

3. Loeys BL, Dietz HC, Braverman AC, Callewaert BL, De Backer J, Devereux RB, et al. The revised Ghent nosology for the Marfan syndrome. J Med Genet. 2010;47(7):476-85

4. Nashef SA, Roques F, Sharples LD, Nilsson J, Smith C, Goldstone AR, et al. EuroSCORE II. Eur J Cardiothorac Surg. 2012;41(4):734-44.

5. Rogers CA, Reeves BC, Caputo M, Ganesh JS, Bonser RS, Angelini GD. Control chart methods for monitoring cardiac surgical performance and their interpretation. J Thorac Cardiovasc Surg. 2004;128:811-9.

6. Michele M, Alfredo G. Cerillo, Stefano Bevilacqua, Danyar Gilmanov, Pierandrea Farneti, Mattia Glauber. Traversing the learning curve in minimally invasive heart valve surgery: a cumulative analysis of an individual surgeon's experience with a right minithoracotomy approach for aortic valve replacement. Eur J Cardiothorac Surg. 2012;6:1242-6.

7. Kouchoukos NT, Wareing TH, Murphy SF, Perrillo JB. Sixteen-year experience with aortic root replacement. Results of 172 operations. Ann Surg. 1991; 214(3):308-18

8. Prifti E, Bonacchi M, Frati G, Proietti P, Giunti G, Babatasi G, et al. Early and long-term outcome in patients undergoing aortic root replacement with composite graft according to the Bentall's technique. Eur J Cardiothorac Surg. 2002;21:15-21.

9. Sioris T, David TE, Ivanov J, Armstrong S, Feindel CM. Clinical outcomes after separate and composite replacement of the aortic valve and ascending aorta. J Thorac Cardiovasc Surg. 2004;128:260-5

10. Etz CD, Bischoff MS, Bodian C, Roder F, Brenner R, Griepp RB, et al. The Bentall procedure: is it the gold standard? A series of 597 consecutive cases. J Thorac Cardiovasc Surg. 2010;140(6 Suppl):S64-70.

11. Joo HC, Chang BC, Youn YN, Yoo KJ, Lee S. Clinical experience with the Bentall procedure: 28 years. Yonsei Med J. 2012;53(5):915-23.

12. Kimura N, Tanaka M, Kawahito K, Itoh S, Okamura H, Yamaguchi A, et al. Early- and long-term outcomes after surgery for acute type a aortic dissection in patients aged 45 years and younger. Circ J. 2011;75(9):2135-43.

13. Agg B, Benke K, Szilveszter B, Polos M, Daroczi L, Odler B, et al. Possible extracardiac predictors of aortic dissection in Marfan syndrome. BMC Cardiovasc Disord. 2014;14:47.

14. Alpendurada F, Wong J, Kiotsekoglou A, Banya W, Child A, Prasad SK, et al Evidence for Marfan cardiomyopathy. Eur J Heart Fail. 2010;12(10):1085-91.

15. Judge DP, Dietz HC. Marfan's syndrome. Lancet. 2005;366:1965-76.

16. Murzi M, Cerillo AG, Bevilacqua S, Gilmanov D, Farneti P, Glauber M. Traversing the learning curve in minimally invasive heart valve surgery: a cumulative analysis of an individual surgeon's experience with a right minithoracotomy approach for aortic valve replacement. Eur J Cardiothorac Surg. 2012:41(6):1242-6.

17. Caputo M, Reeves BC, Rogers CA, Ascione R, Angelini GD. Monitoring the performance of residents during training in off-pump coronary surgery. J Thorac Cardiovasc Surg. 2004;128(6):907-15.

18. Milano AD, Pratali S, Mecozzi G, Boraschi P, Braccini G, Magagnini E, et al. Fate of coronary ostial anastomoses after the modified Bentall procedure. Ann Thorac Surg. 2003;75(6):1797-801.

19. Kazui T, Yamashita K, Terada H, Washiyama N, Suzuki T, Ohkura K, et al. Late reoperation for proximal aortic and arch complications after previous composite graft replacement in Marfan patients. Ann Thorac Surg. 2003; 76(4):1203-7.

20. Gott VL, Greene PS, Alejo DE, Cameron DE, Naftel DC, Miller DC, et al Replacement of the aortic root in patients with Marfan's syndrome. N Engl J Med. 1999;340(17):1307-13.

21. Patel ND, Weiss ES, Alejo DE, Nwakanma LU, Williams JA, Dietz HC, et al. Aortic root operations for Marfan syndrome: a comparison of the Bental and valve-sparing procedures. Ann Thorac Surg. 2008;85(6):2003-10.

\section{Submit your next manuscript to BioMed Central and we will help you at every step:}

- We accept pre-submission inquiries

- Our selector tool helps you to find the most relevant journal

- We provide round the clock customer support

- Convenient online submission

- Thorough peer review

- Inclusion in PubMed and all major indexing services

- Maximum visibility for your research

Submit your manuscript at www.biomedcentral.com/submit 